Supplementary Materials

\title{
A Copper (II) Ion-Selective Fluorescent Sensor Based on Inner Filter Effect Using a Spiropyran Derivative
}

\author{
Na Shao ${ }^{1}$, Ying Zhang ${ }^{1}$, SinMan Cheung ${ }^{2}$, RongHua Yang ${ }^{1 *}$, WingHong Chan ${ }^{2 *}$, Tain \\ $\mathrm{Mo}^{2} \mathrm{KeAn} \mathrm{Li}^{1}$, Feng Liu ${ }^{1}$, \\ ${ }^{1}$ College of Chemistry and Molecular Engineering, Peking University, Beijing, 100871, China ; \\ ${ }^{2}$ Department of Chemistry, Hong Kong Baptist University, Kowloon Tong, Hong Kong, China
}

E-mail: Yangrh@pku.edu.cn, Whchan@hkbu.edu.hk 


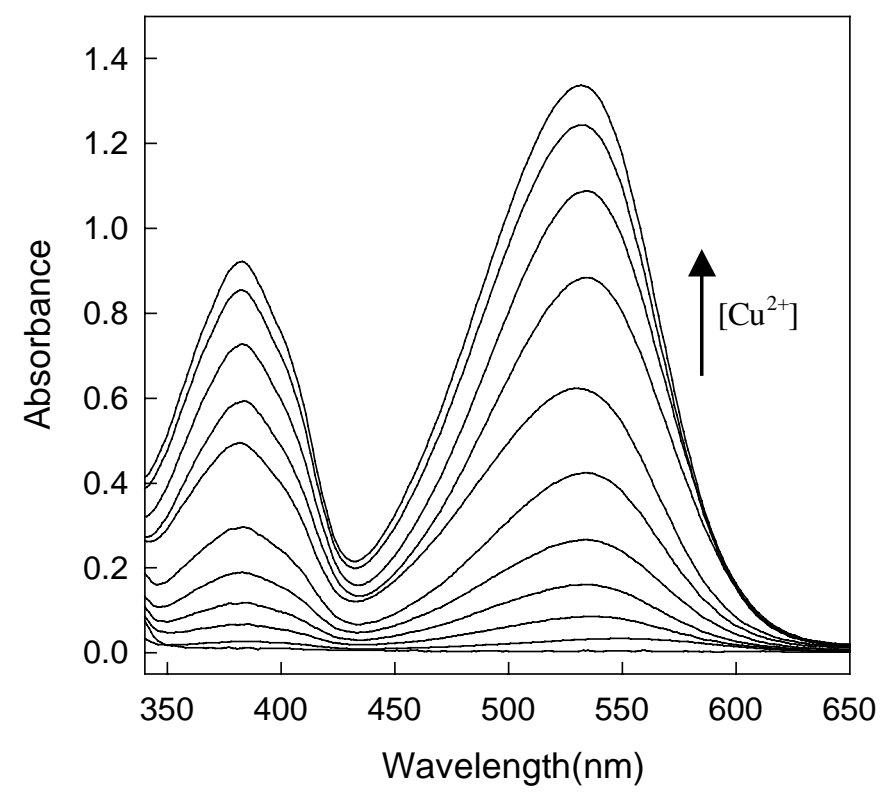

Figure S1 UV-Vis absorption spectra of $1\left(5.0 \times 10^{-5} \mathrm{M}\right)$ in ethanol solution in the presence of different concentrations of $\mathrm{Cu}^{2+}$. The arrows indicate the signal changes as increases in copper ion concentrations $\left(0,1.0 \times 10^{-6}, 2.5 \times 10^{-6}, 5.0 \times 10^{-6}, 1.0 \times 10^{-5}\right.$, $\left.1.5 \times 10^{-5}, 2.5 \times 10^{-5}, 5.0 \times 10^{-5}, 1.0 \times 10^{-4}, 1.5 \times 10^{-4}, 2.5 \times 10^{-4} \mathrm{M}\right)$.

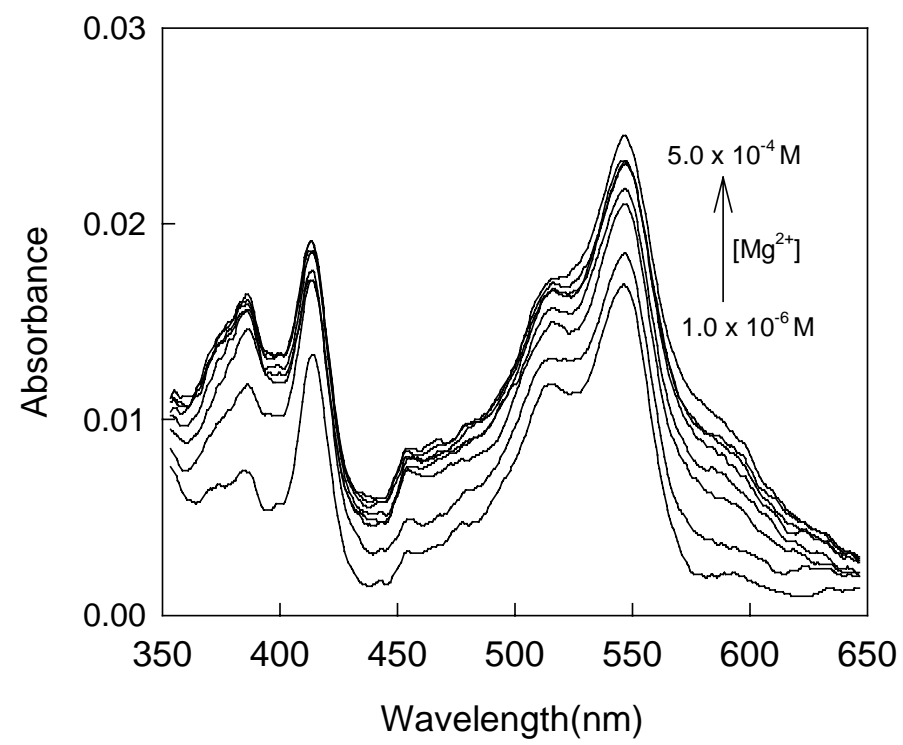

Figure S2 Absorption spectra of $\mathbf{1}$ in ethanol in the presence different concentrations of $\mathrm{Mg}^{2+}$ from $1.0 \times 10^{-6} \mathrm{M}$ to5. $0 \times 10^{-4} \mathrm{M},[\mathbf{1}]=5.0 \times 10^{-5} \mathrm{M}$. 


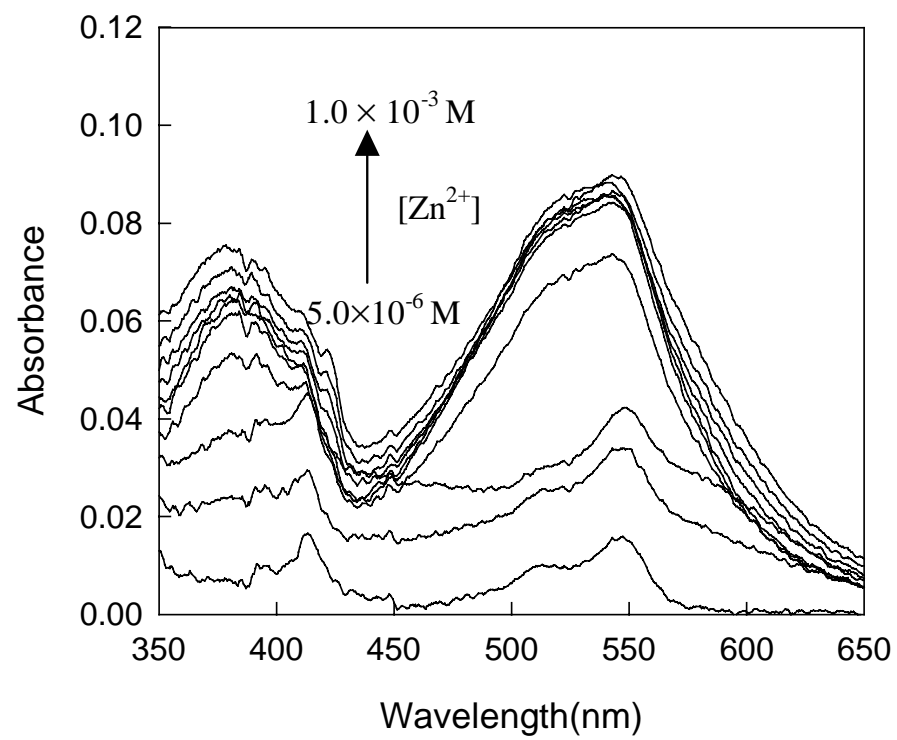

Figure S3 Absorption spectra of $\mathbf{1}$ in ethanol in the presence different concentrations of $\mathrm{Zn}^{2+}$ from $5.0 \times 10^{-6} \mathrm{M}$ to $1.0 \times 10^{-3} \mathrm{M},[1]=5.0 \times 10^{-5} \mathrm{M}$.

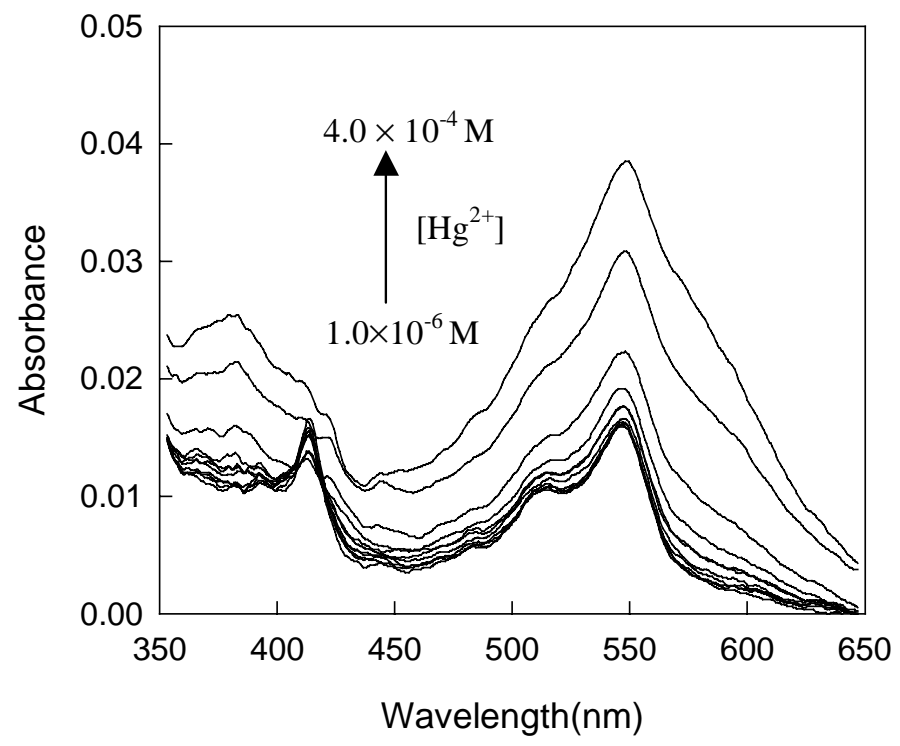

Figure S4 Absorption spectra of $\mathbf{1}$ in ethanol in the presence different concentrations of $\mathrm{Hg}^{2+}$ from $1.0 \times 10^{-6} \mathrm{M}$ to $4.0 \times 10^{-4} \mathrm{M},[\mathbf{1}]=5.0 \times 10^{-5} \mathrm{M}$. 


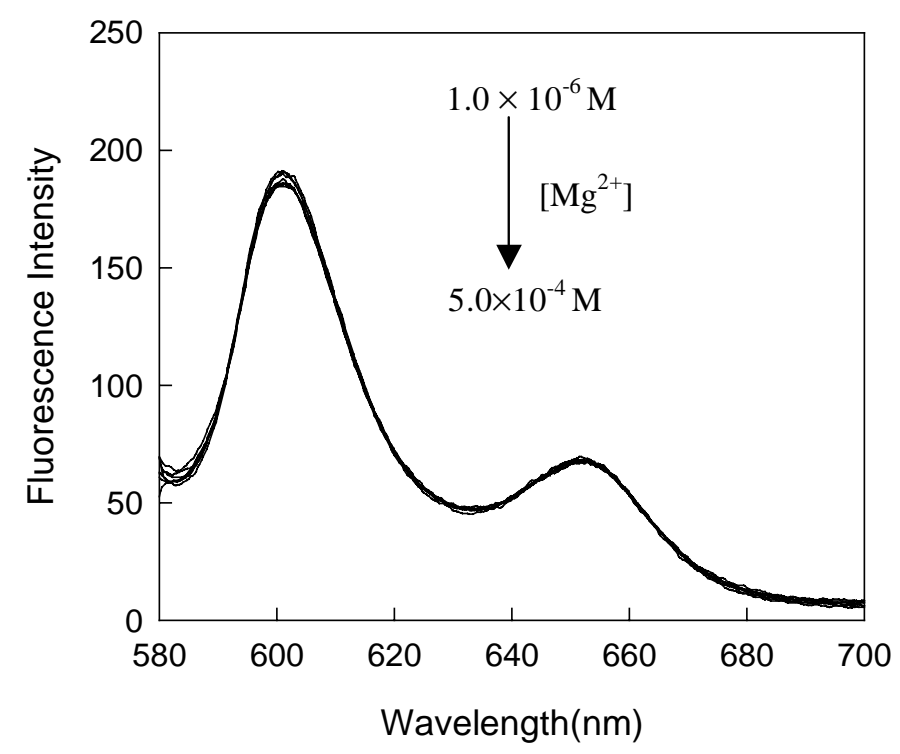

Figure S5 Fluorescence emission spectra of $\mathbf{1}+$ Zntpp in ethanol in the presence different concentrations of $\mathrm{Mg}^{2+}$ from $1.0 \times 10^{-6} \mathrm{M}$ to $5.0 \times 10^{-5} \mathrm{M},[\mathbf{1}]=5.0 \times 10^{-4} \mathrm{M}$, $[$ Zntpp $]=2.5 \times 10^{-6}$ M. $\lambda_{\text {ex }}=556 \mathrm{~nm}$.

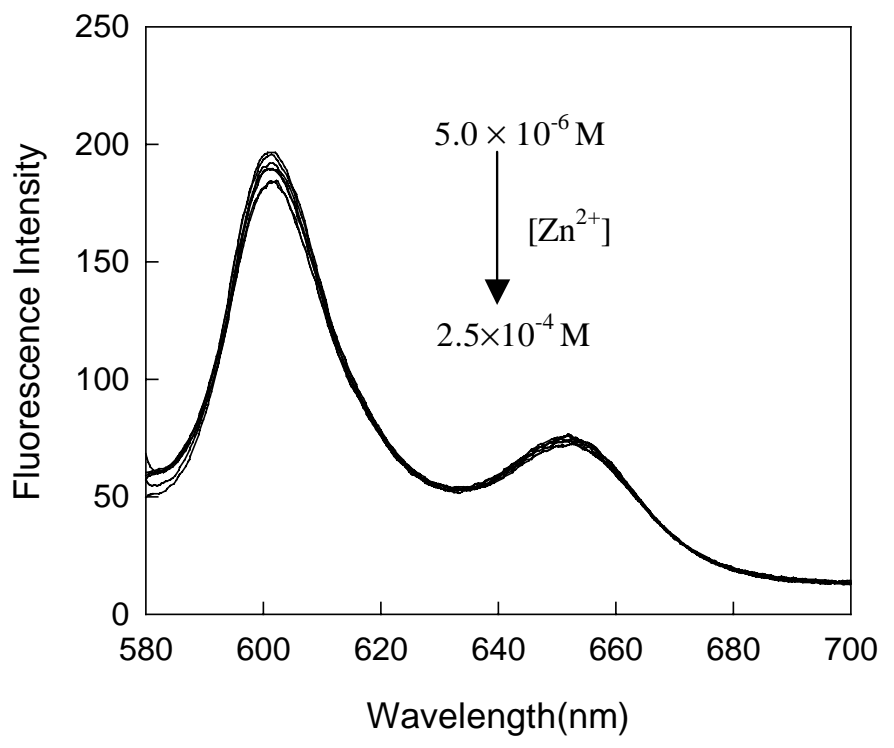

Figure S6 Fluorescence emission spectra of $\mathbf{1}+$ Zntpp in ethanol in the presence different concentrations of $\mathrm{Zn}^{2+}$ from $5.0 \times 10^{-6} \mathrm{M}$ to $2.5 \times 10^{-4} \mathrm{M}$. [1] = $5.0 \times 10^{-5} \mathrm{M}$, $[\mathrm{Zntpp}]=2.5 \times 10^{-6} \mathrm{M} . \lambda_{\mathrm{ex}}=556 \mathrm{~nm}$. 


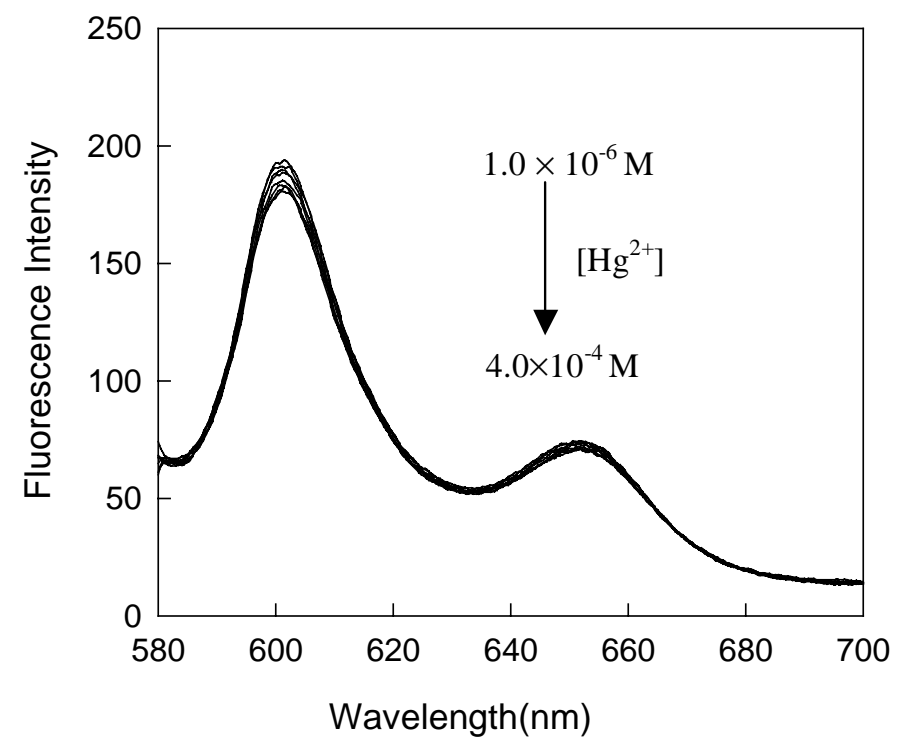

Figure S7 Fluorescence emission spectra of $\mathbf{1}+$ Zntpp in ethanol in the presence different concentrations of $\mathrm{Hg}^{2+}$ from $1.0 \times 10^{-6} \mathrm{M}$ to $4.0 \times 10^{-4} \mathrm{M}$. [1] $=5.0 \times 10^{-5} \mathrm{M}$, $[\mathrm{Zntpp}]=2.5 \times 10^{-6} \mathrm{M} . \lambda_{\mathrm{ex}}=556 \mathrm{~nm}$.

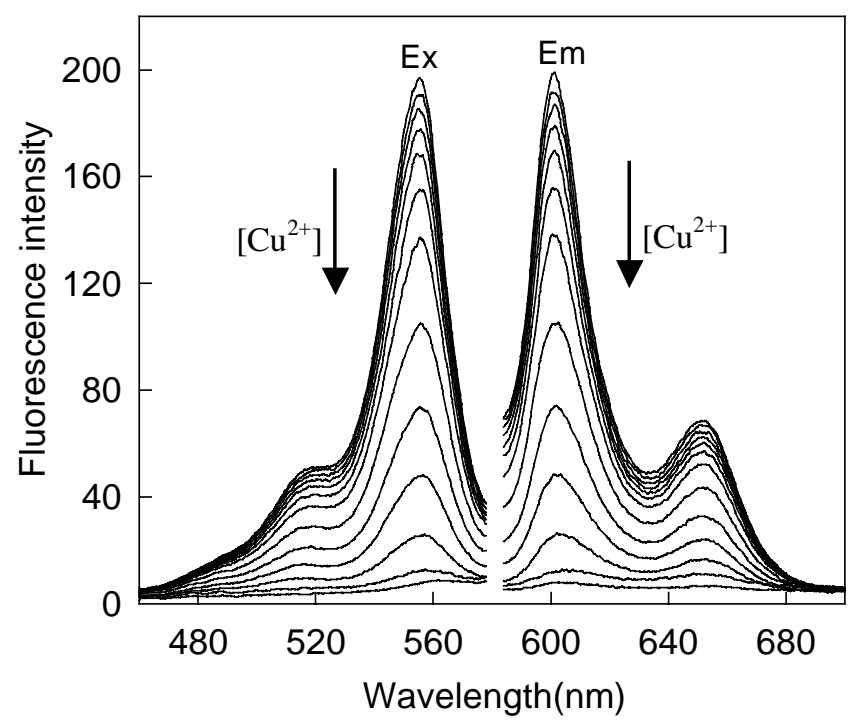

Figure S8 Excitation $\operatorname{spectra}\left(\lambda_{\mathrm{em}}=603 \mathrm{~nm}\right)$ and emission spectra $\left(\lambda_{\mathrm{ex}}=556 \mathrm{~nm}\right)$ of Zntpp in the ethanol solution containing $5.0 \times 10^{-5} \mathrm{M}$ of $\mathbf{1}$ in the presence of different concentrations of copper ion. The arrows indicate the signal changes as increases in copper ion concentrations $\left(0,2.5 \times 10^{-7}, 7.5 \times 10^{-7}, 1.5 \times 10^{-6}, 4.5 \times 10^{-6}, 6.0 \times 10^{-6}, 9.0\right.$ $\left.\times 10^{-6}, 1.2 \times 10^{-5}, 1.8 \times 10^{-5}, 2.4 \times 10^{-5}, 3.6 \times 10^{-5}, 6.0 \times 10^{-5}, 1.2 \times 10^{-4} \mathrm{M}\right)$. The concentration of Zntpp is $2.5 \times 10^{-6} \mathrm{M}$. 


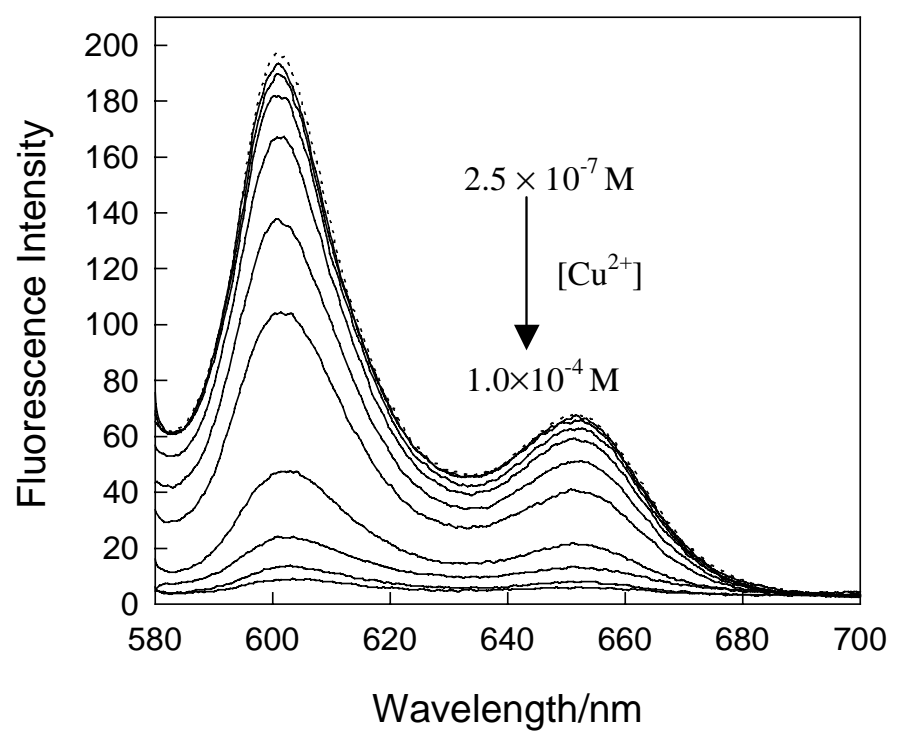

Figure S9 Fluorescence emission spectra of 1+Zntpp in ethanol in the presence of $5 \times 10^{-5} \mathrm{M}$ of $\mathrm{Zn}^{2+}$ with increasing amounts of $\mathrm{Cu}^{2+}$ from $2.5 \times 10^{-7} \mathrm{M}$ to $4.0 \times 10^{-4} \mathrm{M}$ (Dashed line corresponds to the emission of Zntpp without zinc ion as well as copper ion). $[1]=5.0 \times 10^{-5} \mathrm{M},[\mathrm{Zntpp}]=2.5 \times 10^{-6} \mathrm{M} . \lambda_{\mathrm{ex}}=556 \mathrm{~nm}$.

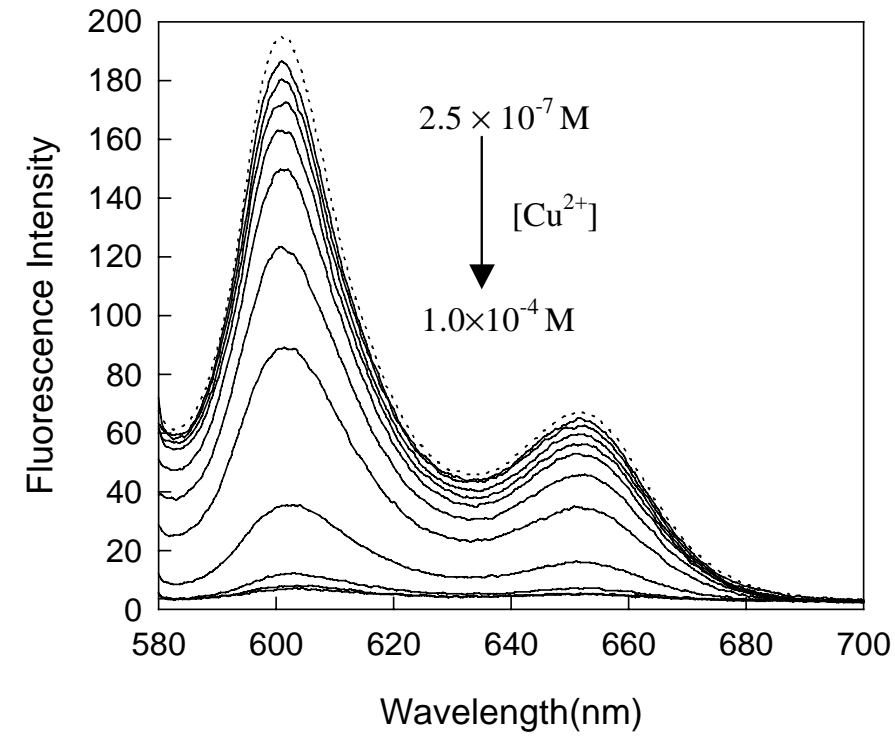

Figure S10 Fluorescence emission spectra of 1+Zntpp in ethanol in the presence of $5 \times 10^{-5} \mathrm{M}$ of $\mathrm{Hg}^{2+}$ with increasing amounts of $\mathrm{Cu}^{2+}$ from $2.5 \times 10^{-7} \mathrm{M}$ to $4.0 \times 10^{-4} \mathrm{M}$ (Dashed line corresponds to the emission of Zntpp without $\mathrm{Hg}^{2+}$ as well as $\mathrm{Cu}^{2+}$ ). [1] = $5.0 \times 10^{-5} \mathrm{M},[\mathrm{Zntpp}]=2.5 \times 10^{-6} \mathrm{M} . \lambda_{\mathrm{ex}}=556 \mathrm{~nm}$. 


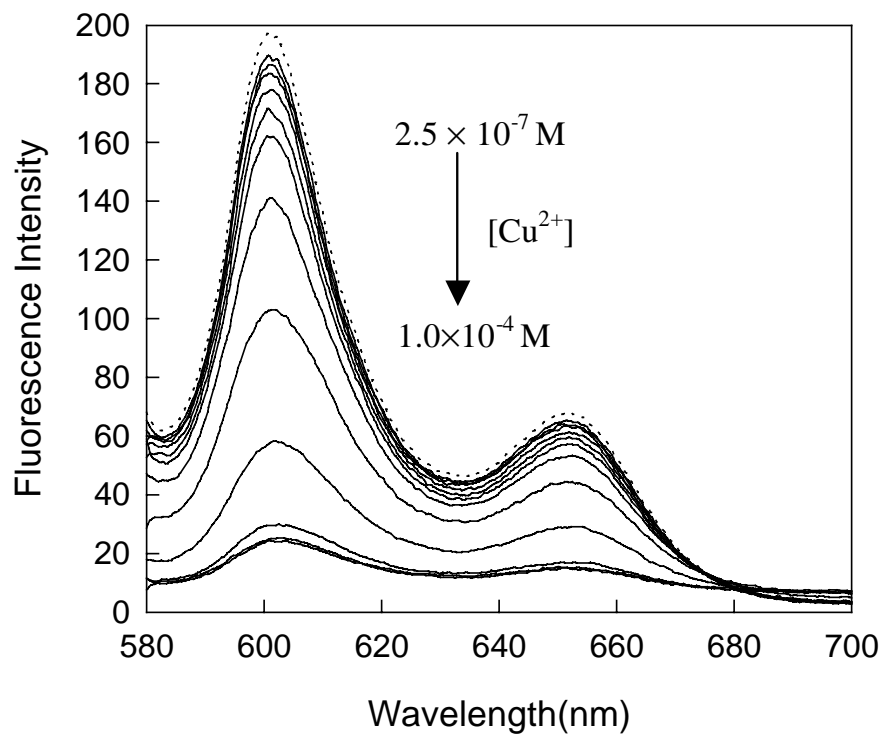

Figure S11 Fluorescence emission spectra of $1+Z n t p p$ in ethanol in the presence of $1 \times 10^{-3} \mathrm{M}$ of $\mathrm{Ca}^{2+}$ and $\mathrm{Mg}^{2+}$, and $5 \times 10^{-5} \mathrm{M}$ of $\mathrm{Hg}^{2+}, \mathrm{Zn}^{2+}$ and $\mathrm{Cd}^{2+}$ with increasing amounts of $\mathrm{Cu}^{2+}$ from $2.5 \times 10^{-7} \mathrm{M}$ to $4.0 \times 10^{-4} \mathrm{M}$ (Dashed line corresponds to the emission of Zntpp without copper ion as well as other interferential metal ions). $[\mathbf{1}]=$ $5.0 \times 10^{-5} \mathrm{M},[\mathrm{Zntpp}]=2.5 \times 10^{-6} \mathrm{M} . \lambda_{\mathrm{ex}}=556 \mathrm{~nm}$.

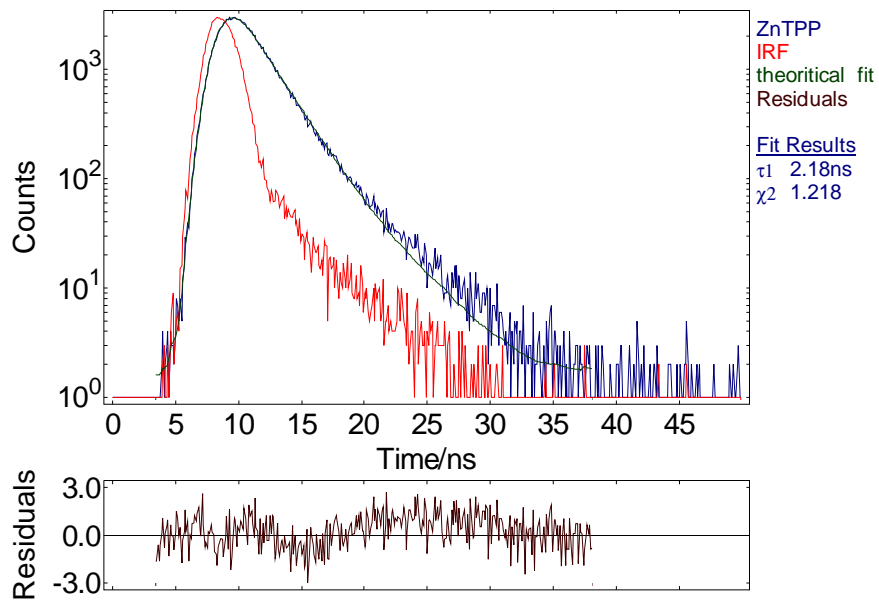

Figure S12 Top: Time-dependent fluorescence decay data of $5 \times 10^{-5} \mathrm{M}$ and $2.5 \times 10^{-6} \mathrm{M}$ Zntpp in ethanol and corresponding fit to a monoexponential decay function. The fitted life-time for the monoexponential decay is $\tau=2.18 \mathrm{~ns}$ and $\chi^{2}$ is 1.218. Bottom: Distribution of the weighed residuals for the monoexponential fit of the fluorescence decay: the porphyrin dye was excited at $556 \mathrm{~nm}$ and the emission was collected at 603 nm. 


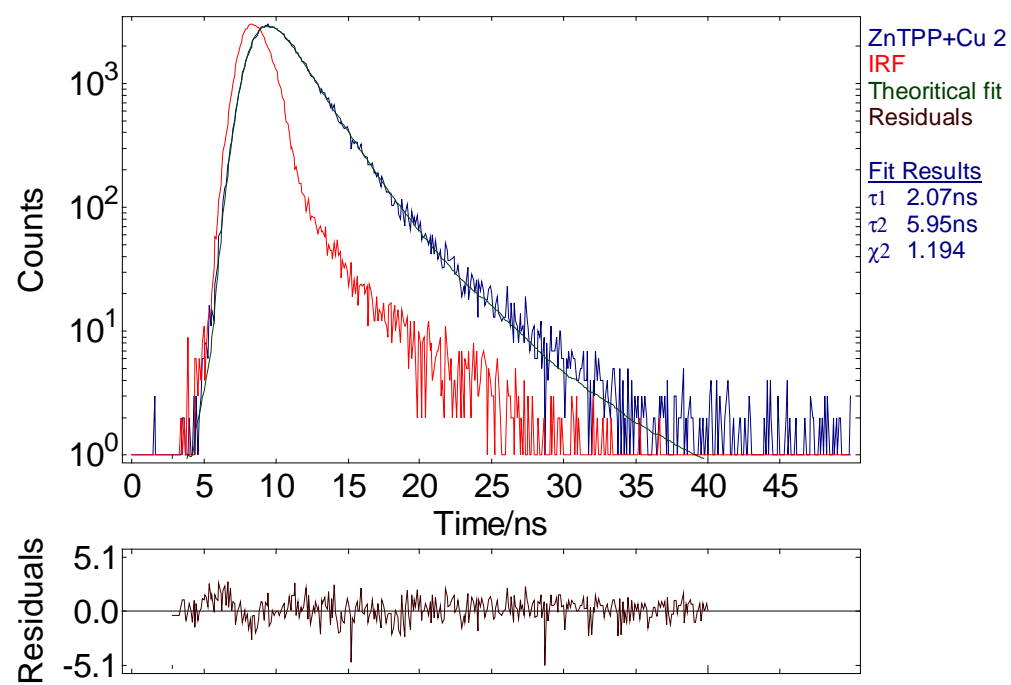

Figure S13 Top: Time-dependent fluorescence decay data of $5 \times 10^{-5} \mathrm{M}$ and $2.5 \times 10^{-6} \mathrm{M}$ Zntpp in ethanol in the presence of $5 \times 10^{-5} \mathrm{M}$ of $\mathrm{Cu}^{2+}$ and corresponding fit to a monoexponential decay function. The fitted life-times for the monoexponential decay are $\tau_{1}=2.07 \mathrm{~ns}(97.3 \%)$ and $\tau_{2}=5.95 \mathrm{~ns}(2.7 \%)$, and $\chi^{2}$ is 1.278 . Bottom: Distribution of the weighed residuals for the monoexponential fit of the fluorescence decay: the porphyrin dye was excited at $556 \mathrm{~nm}$ and the emission was collected at $603 \mathrm{~nm}$. 


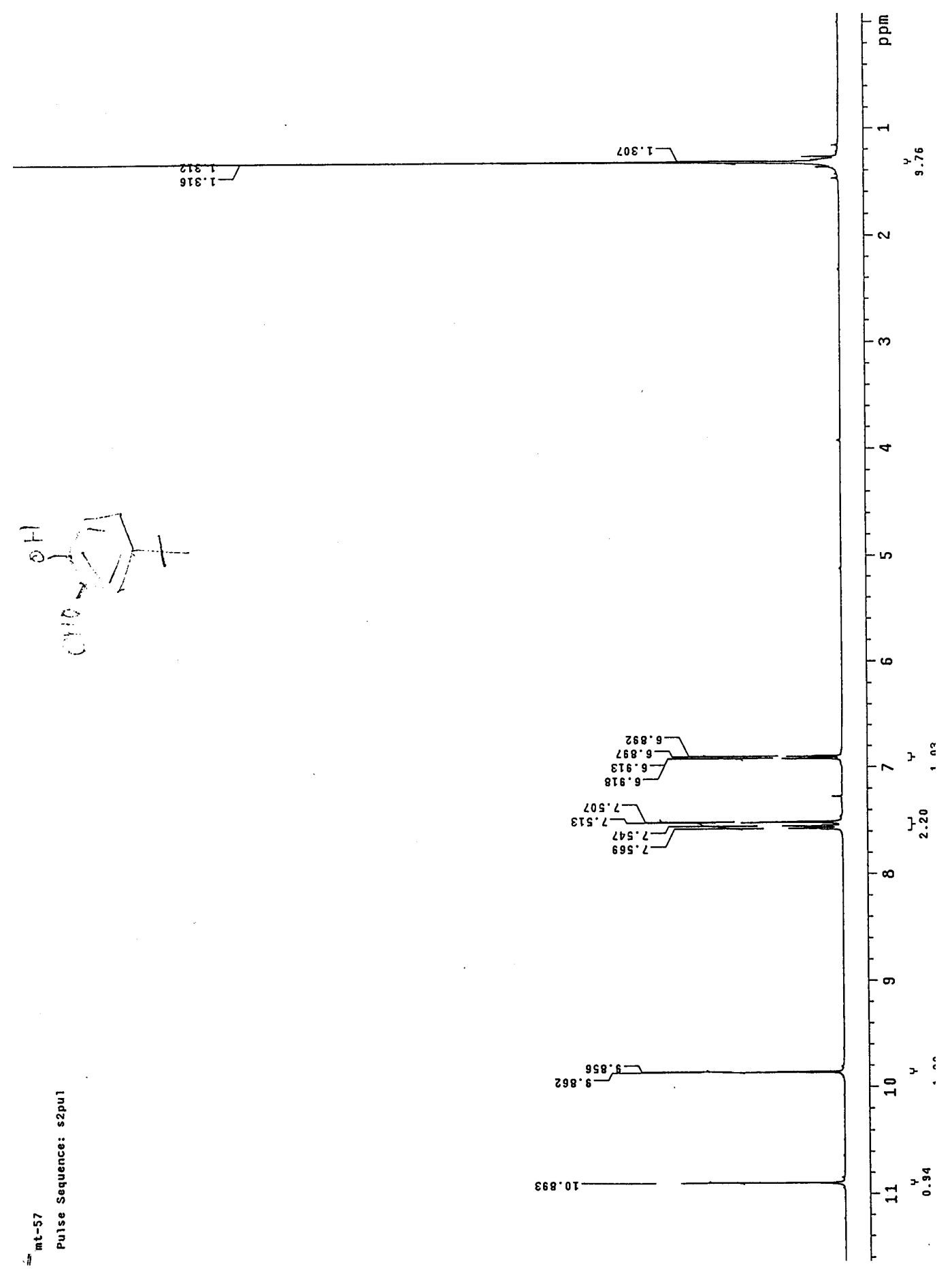

Figure S14 HNMR of compound 4 


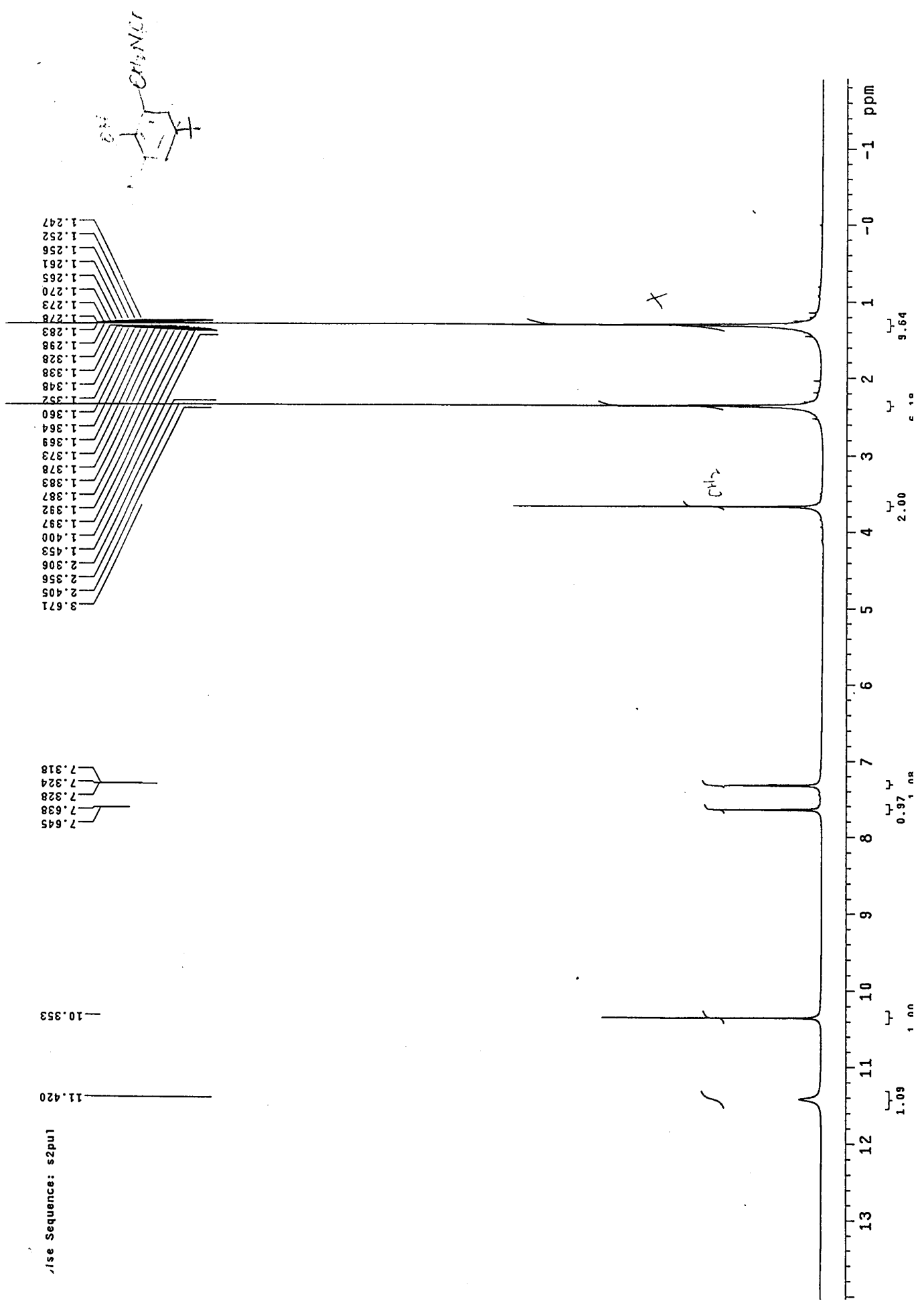

Figure S15 HNMR of compound 5 


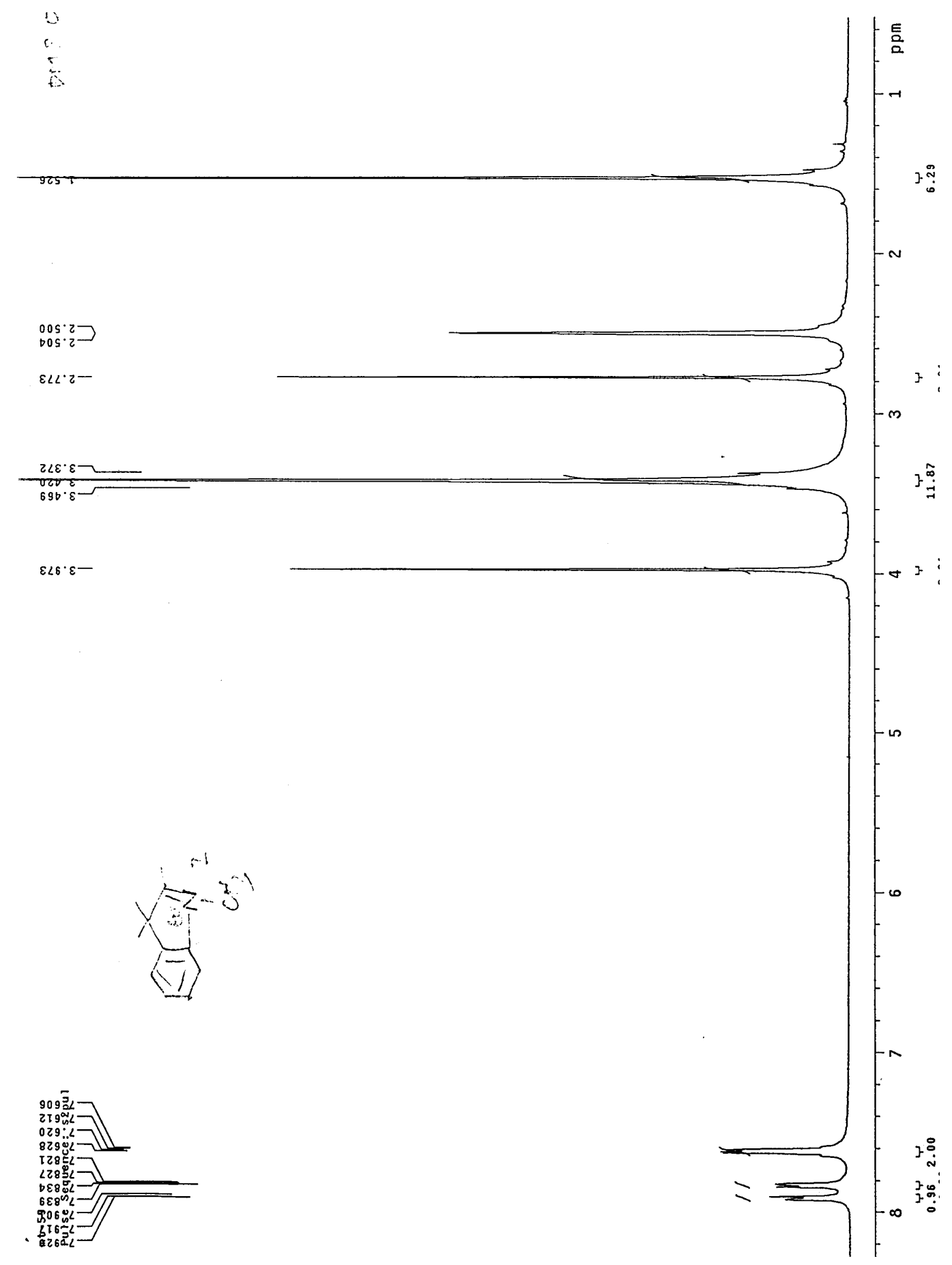

Figure S16 HNMR of compound 7 


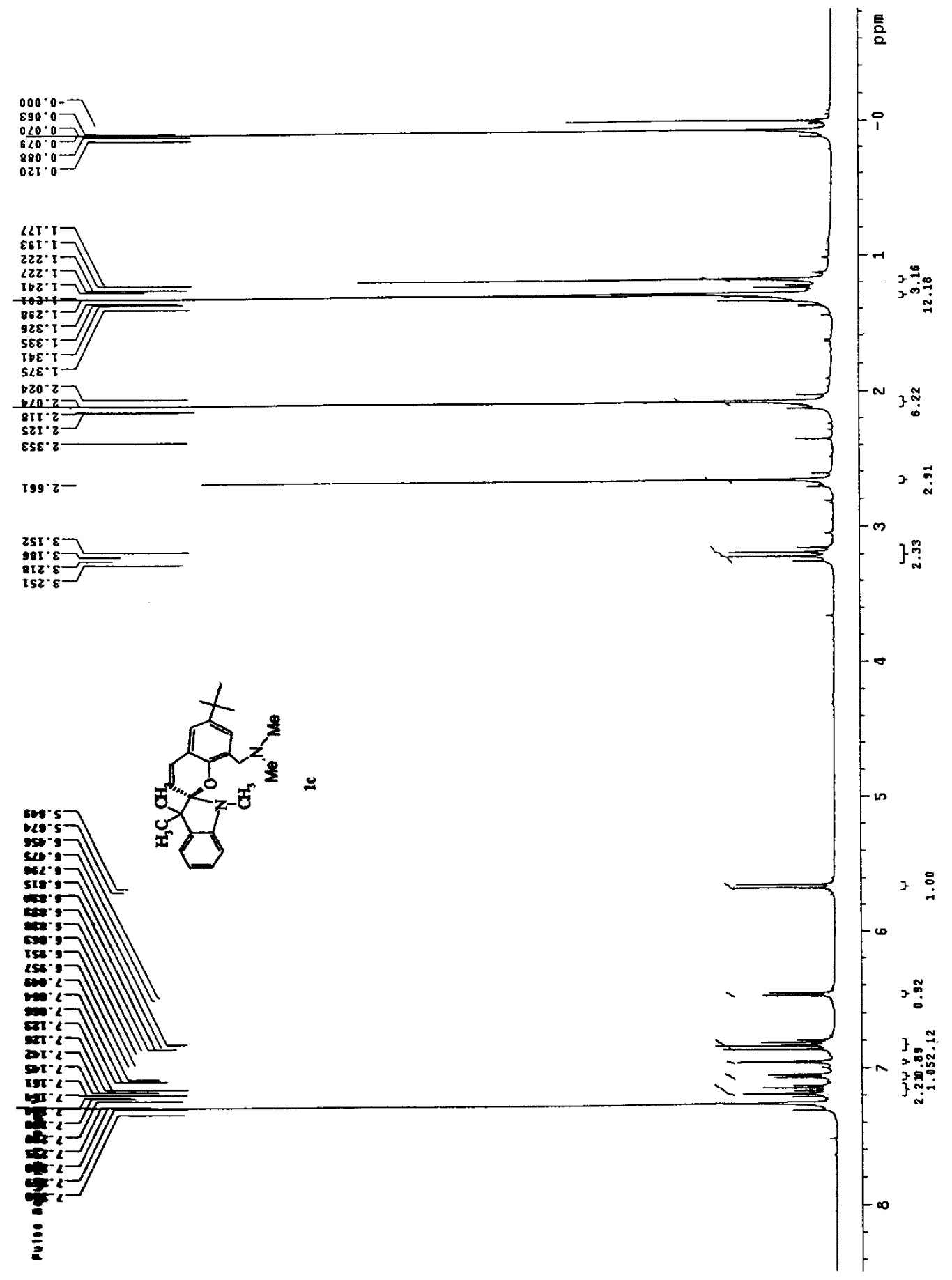

Figure S17 HNMR of sensor 1 